\title{
EDITORIAL
}

\section{The need for research in forensic science}

\author{
Ruth Waddell Smith • Victoria L. McGuffin
}

Published online: 18 June 2009

(C) Springer-Verlag 2009

Since the first episode of "CSI: Crime Scene Investigation" aired in 2000, numerous television shows with forensic science themes have appeared, including two further additions to the CSI franchise (CSI: Miami and CSI: NY). These shows remain popular today and continue to rank in the top 20 ratings for network primetime series. With this popularity, the so-called "CSI Effect" has evolved, in which jurors have higher, and sometimes unrealistic, expectations of the evidence presented at trial. For example, in a survey conducted by Shelton et al., $46 \%$ of prospective jurors expected scientific evidence in every criminal case, and $22 \%$ expected DNA evidence in every criminal case [1].

The recent National Academy of Sciences (NAS) report "Strengthening Forensic Science in the United States: A Path Forward" provides a more realistic assessment of forensic science today [2]. The report highlights current deficiencies and limitations in the community and makes recommendations to secure the future of forensic science. To improve the field for the future, the development of new

R. Waddell Smith $(\bowtie)$

School of Criminal Justice and Department of Chemistry,

Michigan State University,

East Lansing, MI 48824, USA

e-mail: rwsmith@msu.edu

\section{L. McGuffin}

Department of Chemistry, Michigan State University,

East Lansing, MI 48824-1322, USA

e-mail: mcguffin@msu.edu technologies and procedures is recommended, with the NAS calling for "more and better research" to ensure that practices are "strongly rooted in science".

With this special issue on forensic analysis, we aim to highlight emerging research in forensic chemistry. The selection of papers is broad in scope, covering not only new technologies for the analysis of trace evidence but also the application of chemometric procedures for data analysis and interpretation. The papers included are only a sample of the novel and exciting research that is currently being conducted in various academic, state, and federal research laboratories, aiming to enhance current techniques and methodologies for the analysis and interpretation of forensic evidence.

We hope this special issue illustrates that the NAS recommendation of "more and better research" is currently in progress. With additional funding and resources, such research may be further developed and eventually incorporated into crime laboratories for routine analysis. We would like to take this opportunity to sincerely thank all our contributors; this special issue would certainly not have been possible without them.

\section{References}

1. Shelton DE (2008) The 'CSI Effect': Does It Really Exist? National Institute of Justice Journal 259:1-7

2. National Academy of Sciences (2009) Sciences. Strengthening Forensic Science in the United States: A Path Forward. National Academies Press, Washington, D.C 


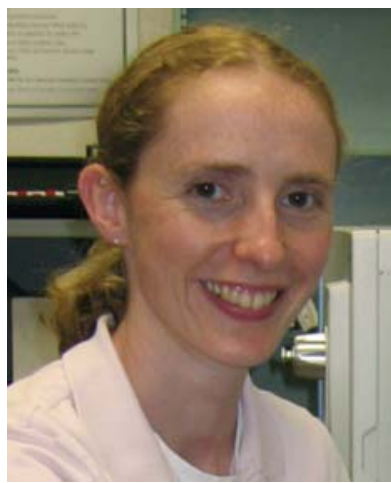

Ruth Waddell Smith is Assistant Professor of Forensic Chemistry in the Forensic Science Program in the School of Criminal Justice at Michigan State University. Her research interests include the application of new and emerging analytical techniques for characterization of forensic evidence and the development of chemometric procedures for association and discrimination of samples of forensic interest.

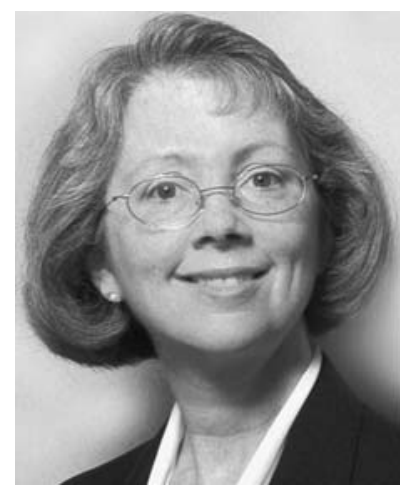

Victoria L. McGuffin is Professor of Chemistry at Michigan State University. Her primary research interests are in the thermodynamic and kinetic basis of chromatography and electrophoresis. She is also interested in the application of chromatography and electrophoresis to problems of forensic and environmental significance. 